\title{
The many faces of mathematics
}

Mathematicians: An Outer View of the
Inner World
by Mariana Cook
Princeton University Press: 2009 .
208 pp. $\$ 35, € 24.95$
Recountings: Conversations with MIT
Mathematicians
by Joel Segel
AK Peters: 2009.330 pp. $\$ 49$

The question of how one makes a great scientific discovery, or teaches others to do so, is central to two recent books that portray mathematicians. In Mathematicians, Mariana Cook photographs more than 90 living mathematicians, each portrait accompanied by an explanation of how they became interested in their subject. Many cite an early introduction to problem solving, often before the age of ten, by a family member. For others, it was a teacher who piqued their interest in mathematics. Later influences came from mentors or leaders in the field - Alexander Grothendeick is named by several as having suggested what they should work on.

Collaboration, such as that between Benedict Gross and Don

Zagier on their eponymous

$\Sigma$ formula or between Isadore Singer and Michael Atiyah on their index theorem, can be decisive in achieving a successful research career. Also important is sustained concentration on a problem: Jean-Pierre Serre says his best work is done at night when halfasleep. A background in music is another frequent theme: Timothy Gowers and Persi Diaconis both come from families of professional musicians, and Noam Elkies and Manjul Bhargava note an early interest in the patterns of Western and Indian classical music, respectively.

Recountings tells of the influential US mathematics department at the Massachusetts Institute of Technology (MIT) through interviews with a dozen faculty members by author Joel Segel. The book was compiled after the sudden early death of Gian-Carlo Rota, MIT professor of applied mathematics and philosophy, when his colleague Gilbert Strang became concerned that reflections on mathematics and the story of the department might be lost with the passing of other senior faculty members. Also interviewed is Zipporah Levinson, the widow of Norman
Levinson, a past department chairman who is revered both for his mathematics and for his able running of the department.

The interest in teaching among these senior faculty members is broad and deep. Many textbooks have arisen from MIT courses, such as George Thomas's classic text Calculus and Analytic Geometry (Addison-Wesley, 1952). The collective pride is palpable as many remember the day in 1959 when maths courses became catalogued as equivalent to others at MIT — no longer carrying an ' $M$ ' prefix to indicate that maths was a service department for the others. The professors share their strategies for achieving research success, from working on prize problems to developing an intuitive feel for proofs. They explain how new research directions have come from interactions with students and colleagues or from writing a review article.

Bertram Kostant's account is particularly inspiring and appears in both books. His interest in science began with his chemistry teacher, Mr Lieberman at Stuyvesant High School in New York, and listing the formulae in chemical reactions. Wherever Kostant went - from college at Purdue University, by way of the University of Chicago, the Institute for Advanced Study in Princeton, the University of California, Berkeley, to MIT - he found himself in the midst of a maths department at a high point. He was also tied to history. At Purdue he was taught by Arthur Rosenthal, a German refugee who had previously taught physicist Werner Heisenberg and had studied under C. L. F. Lindemann - who proved that $\pi$ is not an algebraic number. Years later at Princeton, Kostant drove Albert Einstein home just a week before Einstein's sudden death. Lingering in the car, Einstein asked Kostant what he worked on. "Lie groups," he replied, to which Einstein responded, "Oh, that will be very important." The great man's prophetic reply shows that his legendary intuition extended from physics to mathematics. On a different scale, the insights in these two books will inspire mathematicians and scientists to come.

Eric L. Altschuler is assistant professor in the Department of Physical Medicine and Rehabilitation at the University of Medicine \& Dentistry of New Jersey, New Jersey 07103, USA. e-mail: eric.altschuler@umdnj.edu

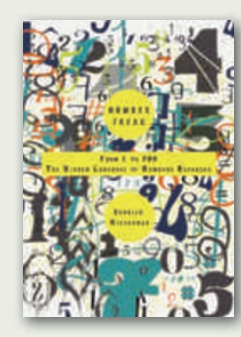

In Number Freak (Perigee Books, 2009), Derrick Niederman tells the stories behind the numerals 1 to 200. Each number gets an entry, detailing its significance from ancient myth to mathematical reality. For instance, the prime number 17 is considered unlucky in Italy and was detested by the Pythagoreans compared with its neighbours 16 and 18; yet the choreographer George Balanchine saw its beauty in a doublediamond configuration of 17 dancers in his ballet Serenade.

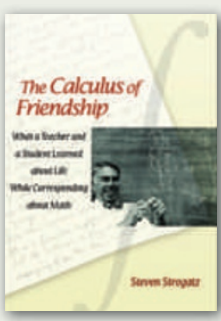

An intimate view of mentorship is revealed by US mathematician Steven Strogatz in The Calculus of Friendship (Princeton University

Press, 2009), a compilation of letters exchanged with his high-school maths teacher over 30 years. Through their correspondence they share problems in calculus, chaos theory and major life events, from professional and sporting successes to family bereavements and divorce. The book touchingly charts their changing roles and relationship, from student to professor, teacher to retirement.

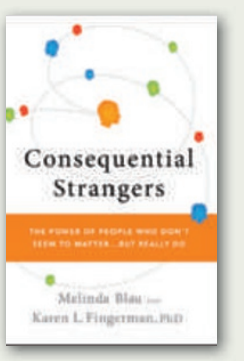

Numerous contacts with neighbours or workmates have a profound effect on our success, happiness and health, according to journalist Melinda Blau and psychologist Karen Fingerman. In Consequential Strangers (W. W. Norton, 2009), they explain how casual acquaintances are most likely to tip you off about a new job or provide a creative solution to a problem. Even though wide social networks can encourage bullying, lying and gossip, they enable people to become more conscious of their shared humanity. 